\title{
In memoriam Claude François Baudez. Maîtriser le temps
}

\section{(2) OpenEdition Journals}

Édition électronique

URL : http://journals.openedition.org/jsa/15285

DOI : 10.4000/jsa. 15285

ISSN : 1957-7842

Éditeur

Société des américanistes

Référence électronique

"In memoriam Claude François Baudez. Maîtriser le temps », Journal de la Société des américanistes [En ligne], Maya times | 2017, mis en ligne le 31 décembre 2017, consulté le 24 septembre 2020. URL

http://journals.openedition.org/jsa/15285 ; DOI : https://doi.org/10.4000/jsa.15285 


\title{
In memoriam Claude François Baudez
}

\author{
Il ne fait pas de doute que non seulement les Mayas représentent le \\ temps au moyen d'un parcours dans l'espace, mais qu'en outre, des \\ déambulations ont lieu à l'achèvement des cycles. \\ Le rite a pour objet de maîtriser le temps et, surtout, d'en assurer la \\ continuité, en évitant les ruptures.
}

Claude F. Baudez, Une histoire de la religion des Mayas, Albin Michel, Paris, 2002, p. 330.

\section{« Maîtriser le temps »}

Le colloque international organisé par le Groupe d'enseignement et de recherche sur les Mayas et la Mésoamérique (GERM) et le musée du quai Branly, qui s'est tenu un peu plus d'un an après la mort de Claude F. Baudez, notre collègue et notre ami, lui a été dédié. Une autre façon de maîtriser le temps, par la mémoire. Cet opus voudrait être la trace de notre respect, de notre admiration et de notre amitié à son égard.

Le travail de C. F. Baudez, vaste et divers, est un exemple pour nous tous, lui qui manifestait sa constante curiosité envers ce qui fait la Mésoamérique dans son histoire et sa culture, mais aussi dans les productions artistiques qu'elle a léguées à l'humanité. Ses contributions n'ont pas fini de nourrir de nouvelles questions. Par plusieurs chemins de la recherche, qui associent notamment l'archéologie et l'iconologie, il a pu proposer bien des éclairages, inventifs mais prudents, sur les religions mayas - il tenait beaucoup au pluriel. Avec un appétit pour la discussion et une complicité sans faille avec tous ceux qui interrogent l'anthropologie, l'histoire, l'art et, bien sûr, l'archéologie, Claude a inlassablement contribué aux trois principes du groupe de collègues dont il était une cheville ouvrière : confrontation et collaboration entre disciplines, comparaison du proche au loin, partage des connaissances et enseignement. Durant toute sa vie, il a représenté et communiqué à la fois l'inquiétude et l'allégresse qui donnent des regards neufs dans tout travail scientifique. 